\title{
Clinico pathological and immunohistochemical study in odontogenic cysts and ameloblastoma (using laminin-1)
}

\author{
Amani Nour El-Din Abd El-Latif ${ }^{1}$, Sahar Mohamed Elsheikh ${ }^{1,2}$, Hashem Mohamed Hassouna ${ }^{1,3}$ \\ ${ }^{1}$ Oral Pathology, Faculty of Dentistry, Pharos University in Alexandria, Egypt \\ ${ }^{2}$ Oral Pathology, Faculty of Dentistry. Alexandria Egypt \\ ${ }^{3}$ L Oral Maxillofacial surgery, Faculty of Dentistry, Pharos University in Alexandria, Egypt
}

Email address:

Amany.noureldin@pua.edu.eg(A. N. E. A. El-Latif), sahar.elsheikh@gmail.com(S. M. Elsheikh), hachem.hassouna@pua.edu.eg(H. M. Hassouna)

\section{To cite this article:}

Amani Nour El-Din Abd El-Latif, Sahar Mohamed Elsheikh, Hashem Mohamed Hassouna. Clinico Pathological and Immunohistochemical Study in Odontogenic Cysts and Ameloblastoma (Using Laminin-1). American Journal of Life Sciences . Vol. 1, No. 3, 2013, pp. 130-135. doi: 10.11648/j.ajls.20130103.19

\begin{abstract}
Odontogenic cysts, keratocystic odontogenic tumor and ameloblastoma are the most common forms of cystic lesions and tumors that affect the jaw bones region. Demographic profiles of these lesions have been reported in various age groups in several countries, however, few reports can be found among Egyptian population. The purpose of this study is to evaluate the prevalence of odontogenic cysts, keratocystic odontogenic tumor and ameloblastoma in patients seeking treatment in Faculty of Dentistry of Alexandria and Pharos Universities, Alexandria, Egypt in the last four years (2009-2012).To study odontogenic cysts, keratocystic odontogenic tumor and ameloblastoma clinically and histopathologically as well as to detect the immunoexpression of laminin-1. A clinical and a retrospective survey were carried out. For immunostaining, sections were immunostained with anti-laminin-1 primary antibody (\#RB-082-A) according to manufactures, instructions. Statistical analysis was carried out on the tabulated data using (SPSS 16.0) software. It was found that the incidence of odontogenic cysts, keratocystic odontogenic tumor and ameloblastoma in male is slightly more than that in female, and the mandible was the most frequent affected side. Keratocystic odontogenic tumors and unicystic ameloblastoma were considered the most prevalent odontogenic tumors with an increase in the incidence of ameloblastic carcinoma in the last four years. The benign nature of some odontogenic cysts and the aggressive behavior of others could be explained by the expression of laminin-1 that may indicate that it might be valuable markers for the prediction of the biologic behavior of cystic lesions.
\end{abstract}

Keywords: Odontogenic Cysts, Keratocystic Odontogenic Tumors, Ameloblastoma, Laminin-1

\section{Introduction}

Odontogenic cysts are the most common form of cystic lesions that affect the jaw bones region. They are classified traditionally into a developmental group, Including Gorlin cyst and dentigerous cysts, as well as an inflammatory group including radicular cysts. Developmental cysts are usually asymptomatic, but have the potential to become extremely large and cause cortical expansion and erosion. ${ }^{(1)}$ Keratocystic odontogenic tumor (KCOT) defined by the World Health Organization (WHO), as a benign, intraosseous neoplasm of dental origin, with a characteristic lining of parakeratinized stratified squamous epithelium. The increase in the activity of the epithelium has been confirmed by previous studies that have compared KCOTs with other odontogenic cysts. This might explain the high recurrence rates of the KCOTs. ${ }^{(2)}$

Ameloblastoma is the most common odontogenic tumor with a variety of microscopic subtypes. Histopathologic variants of ameloblastoma include follicular, plexiform, acanthomatous, granular and desmoplastic patterns. Despite histopathological diversity, behaviors of these subtypes have few differences ${ }^{(3)}$. Ameloblastic carcinoma is a rare malignant lesion with characteristic histologic features and behavior that dictates a more aggressive surgical approach than that of a simple ameloblastoma. ${ }^{(4)}$

Expression of laminin-1 in normal oral mucosa, odontogenic cysts and odontogenic tumors was examined in several studies. In previous studies, it was found that sections of odontogenic tumors stained for laminin-1 
showed strong reactivity at the basement membrane junction as well as in the cytoplasm of all tumor cells. Accordingly, it was suggested that the expression of laminin-1 in the cytoplasm of the tumor cells, but not in the normal mucosa may be a useful marker to distinguish these two types of epithelium. ${ }^{(5)}$ This may suggest that laminin-1 influences the proliferation activity toward tumor potential. $^{(5,6)}$

Demographic profiles of odontogenic cysts and ameloblastoma have been reported in various age groups in several European and non-European countries ${ }^{(7-9)}$ however, few reports can be found among Egyptian population. ${ }^{(10)}$ The purpose of this study is to evaluate the prevalence of odontogenic cysts,Keratocystic odontogenic tumor and ameloblastoma in patients seeking treatment in Faculties of Dentistry, Alexandria Egypt in the last four years (2009-2012). To study odontogenic cysts, Keratocystic odontogenic tumor and ameloblastoma clinically and histopathologically as well as to detect the immunoepxression of laminin-1 in radicular cysts (RCs),Keratocystic odontogenictumor (KOTs) Dentigerous cyst, Glandular odontogenic cyst and ameloblastoma .Finally, to examine the possible predictive value of this marker.

\section{Materialand Methods}

A clinical as well as retrospective survey was carried out among patients who attended the Departments of Cranio Maxillofacial and Plastic Surgery, Faculty of Dentistry University of Alexandria, Egypt and Oral Surgery Faculty of Dentistry, Pharos University, Alexandria Egypt in the last four years (2009-2012).

A total of 162 cases were diagnosed as odontogenic cysts and tumors of the jaws based on clinical, radiologic and histopathologic examination. Data were retrieved from patients' clinical files, including imaging (pano-ramic and periapical radiographs in all cases, computerized tomography and 3 dimensions in some cases) and histopathology records from Oral Pathology department Faculty of Dentistry, Alexandria, Egypt.

In every case the following information was obtained: age, gender, type and location.

\subsection{Immunohistochemical analysis}

For immunohistochemical study, 10 cases of inflammatory cysts, six dentigerous cysts, a case of glandular odontogenic cyst, seven Keratocytic odontogenic tumors, sixameloblastoma and 4ameloblastic carcinoma were included.

For all specimens $5 \mu \mathrm{m}$ sections were cut and mounted on positively charged glass slides. Sections were deparaffinized with xylene and rehydrated in graded ethyl alcohol, sections were immersed in citrate buffer solution of $\mathrm{pH} 4.8$ and were put in the microwave oven before staining procedures.

For immunostaining a universal kit (R\&D Systems; USA) was used, peroxidase anti- peroxidase method of immunostaining using the streptavidin-biotin system was carried out, $3 \%$ hydrogen peroxide was applied to the sections to block the endogenous peroxidase activity. The sections were immunostained with anti-laminin-1 primary antibody (\#RB-082-A). The tissue sections were incubated over night at room temperature. Sections were then covered by the link antibody followed by the streptavidin labeling antibody. After rinsing with PBS, DAB chromogen was applied to the sections followed by counter stain, and then sections were dehydrated in graded alcohol, cleared in xylene and mounted.

Statistical analysis was carried out on the tabulated data using (SPSS 16.0) software.

\section{Results}

\subsection{Clinical Results}

Of the thousands of individuals admitted during the period of study, a totalof129 cysts and Keratocystic odontogenic tumor were diagnosed as well as33 cases of ameloblastoma.(Figs. 1-3).Concerning those having odontogenic cysts and keratocytic odontogenic tumor, 84 were males $(64.8 \%)$ and 45 werefemales $(35.2 \%)$. Their age incidence ranges from 6-74 years. (Mean \pm SD $32.63 \pm$ 15.33 and Median30.50)(Table1). Sixty two (48.5\%) affect the maxilla while $67(51.5 \%)$ affect the mandible.

Table (1). Description of the studied cases according to demographic data in 2009 to 2012 years.

\begin{tabular}{|c|c|c|c|c|c|c|c|c|c|c|}
\hline & \multicolumn{2}{|c|}{$\begin{array}{c}2009 \\
(n=30)\end{array}$} & \multicolumn{2}{|c|}{$\begin{array}{c}2010 \\
(n=34)\end{array}$} & \multicolumn{2}{|c|}{$\begin{array}{c}2011 \\
(n=24)\end{array}$} & \multicolumn{2}{|c|}{$\begin{array}{c}2012 \\
(n=41)\end{array}$} & \multicolumn{2}{|c|}{ Total } \\
\hline & No & $\%$ & No & $\%$ & No & $\%$ & No & $\%$ & No & $\%$ \\
\hline \multicolumn{11}{|l|}{ Sex } \\
\hline Male & 16 & 53.3 & 22 & 64.7 & 15 & 62.5 & 31 & 75.6 & 83 & 64.8 \\
\hline $\begin{array}{l}\text { Female } \\
\text { Age }\end{array}$ & 14 & 46.7 & 12 & 35.3 & 9 & 37.5 & 10 & 24.4 & 45 & 35.2 \\
\hline Min. - Max. & \multirow{3}{*}{\multicolumn{2}{|c|}{$\begin{array}{c}7.0-64.0 \\
33.03 \pm 14.92 \\
34.5\end{array}$}} & \multirow{3}{*}{\multicolumn{2}{|c|}{$\begin{array}{c}6.0-74.0 \\
31.15 \pm 16.95 \\
29\end{array}$}} & \multirow{3}{*}{\multicolumn{2}{|c|}{$\begin{array}{c}9.0-74.0 \\
35.62 \pm 16.19 \\
34\end{array}$}} & \multirow{3}{*}{\multicolumn{2}{|c|}{$\begin{array}{c}12.0-60.0 \\
31.80 \pm 13.93 \\
28.5\end{array}$}} & \multirow{3}{*}{\multicolumn{2}{|c|}{$\begin{array}{c}6.0-74.0 \\
32.63 \pm 15.33 \\
30.5\end{array}$}} \\
\hline Mean \pm SD & & & & & & & & & & \\
\hline Median & & & & & & & & & & \\
\hline
\end{tabular}




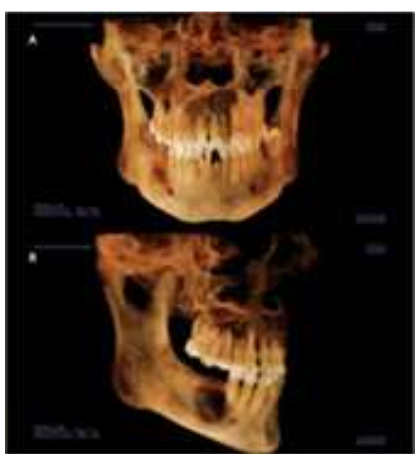

Figure 1. (A) Postero-Anterior view showing expansion of the buccal plate and relation of the lesion to mandibular canal. (B) Lateral view with well circumscribed radiolucent area in relation to second premolar. Notice the approximation of the lesion to the mandibular canal vessels.

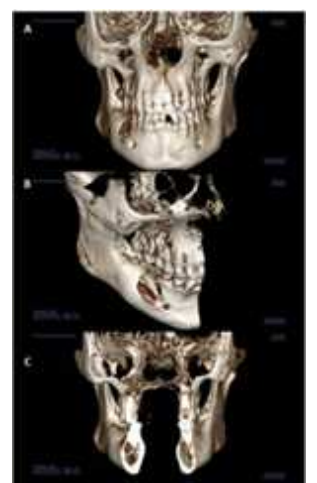

Figure 2. (A) Three dimensional postero-anterior view with relevant appearance of buccal expansion with bone destruction. (B)Three dimensional Lateral views showing buccal bone expansion. (C)Three dimensional view (axial cut) showing expansion of buccal plate of bone with multilocular appearance while lingual plate intact.

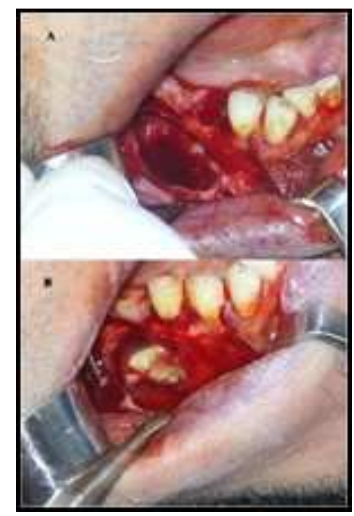

Figure 3. Clinical view of Keratocystic odontogenic tumor. The yellow color denotes the cyst lining.

Concerning ameloblastoma, 17 were male (51.51\%) and 16 were female $(48.49 \%)$. Their age incidence ranges from 9-47 years old. $18(54.55 \%)$ of which affect the mandible, and $15(45.45 \%)$ affect the maxilla.

\subsection{Histopathological Results}

Regarding odontogenic lesions, $25.8 \%$ were inflammatory cyst, a case of which was recurrent due to incomplete removal of the primary one. $12.5 \%$ were diagnosed as dentigerous cyst. and 3.1\% was Gorlin cyst. Only one case was a glandular odontogenic cyst representing $2.4 \%$. 32.8\% of cases were diagnosed as Keratocystic odontogenic tumor and finally $25.8 \%$ were diagnosed as ameloblastoma. (Table2). Histopathological differentiationof ameloblastoma, was summarized in (Fig 4).

Table (2). Description of the studied cases according diagnosis in 2009 to 2012 years.

\begin{tabular}{|c|c|c|c|c|c|c|c|c|c|c|}
\hline \multirow{2}{*}{ Diagnosis } & \multicolumn{2}{|c|}{$\begin{array}{c}2009 \\
(n=30)\end{array}$} & \multicolumn{2}{|c|}{$\begin{array}{c}2010 \\
(n=34)\end{array}$} & \multicolumn{2}{|c|}{$\begin{array}{c}2011 \\
(n=24)\end{array}$} & \multicolumn{2}{|c|}{$\begin{array}{c}2012 \\
(n=41)\end{array}$} & \multicolumn{2}{|c|}{ Total } \\
\hline & No & $\%$ & No & $\%$ & No & $\%$ & No & $\%$ & No & $\%$ \\
\hline Inflammatory cyst & 5 & 16.7 & 10 & 29.4 & 4 & 16.7 & 14 & 34.1 & 33 & 25.8 \\
\hline Dentigerous cyst & 4 & 13.3 & 5 & 14.7 & 2 & 8.3 & 5 & 12.2 & 16 & 12.5 \\
\hline Glandularodontogenic cyst & 0 & 0 & 0 & 0 & 0 & 0 & 1 & 2.4 & 1 & 2.4 \\
\hline Gorlin cyst & 0 & 0 & 2 & 5.9 & 1 & 4.2 & 1 & 2.4 & 4 & 3.1 \\
\hline $\begin{array}{l}\text { Keratocystic odontogenic } \\
\text { tumor (KCOT) }\end{array}$ & 11 & 36.7 & 13 & 38.2 & 6 & 25 & 7 & 17.1 & 37 & 28.9 \\
\hline $\begin{array}{l}\text { Recurrent Keratocystic } \\
\text { odontogenic tumor }\end{array}$ & 0 & 0 & 0 & 0 & 3 & 12.5 & 2 & 4.9 & 5 & 3.9 \\
\hline Ameloblastoma & 10 & 33.3 & 4 & 11.8 & 8 & 33.3 & 11 & 26.8 & 33 & 25.8 \\
\hline
\end{tabular}

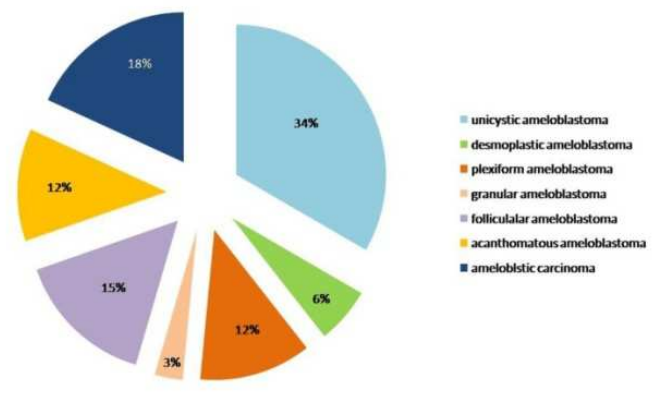

Fig 4. Histopathological differentiation of ameloblastoma.

\subsection{Immunohistochemical Analysis}

A total of 34 cases of odontogenic lesions were included in the present work.50\% were diagnosed as odontogenic cyst, while $38.23 \%$ were benign odontogenic tumors and only $11.76 \%$ were malignant odontogenic tumors.

The odontogenic cysts were divided into 10 of inflammatory, 6 dentigerous and one glandular odontogenic cyst. Thirteen cases of benign odontogenic tumors were included in this study. Six cases were ameloblastoma and 7 cases were diagnosed as Keratocystic odontogenic tumor. Ameloblastic carcinoma represents 4 cases. 
All the examined sections of odontogenic cysts showed positive reaction toLaminin-1. The immunopositive reaction appeared as brown linear staining at the basement membrane of the epithelial cells in most of the cases. Few cases, exhibited positive immunoreactivity at the basement membrane junction as well as in the cytoplasm of epithelial cells. (Figs. 5-7).Concerning benign odontogenic tumors, $50 \%$ of the examined cases of Keratocystic odontogenic tumors were immune reactive to laminin 1 . However, $60 \%$ of ameloblastoma showed positive reaction (Fig.8). Two cases of ameloblastic carcinoma were immunoreactive (Fig. 9).

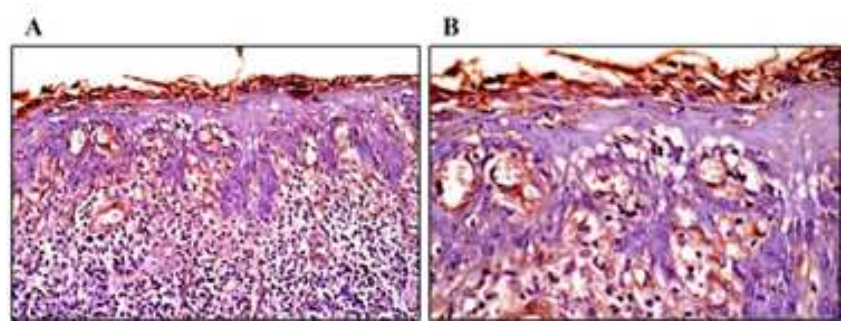

Figure 5. A photomicrograph showing laminin-1 expression in the cytoplasm of epithelial cells in an inflammatory cyst. ( (A) laminin-1 $\times 20$. (B) laminin-1 × 40.)

A

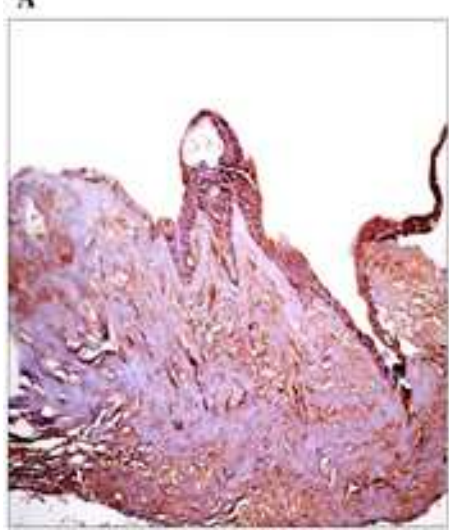

Figure 6. A photomicrograph of glandular odontogenic cyst, exhibiting positive immunoreactivity at the basement membrane junction as well as in the cytoplasm of epithelial cells..(A. Laminin-1X20-B.Laminin-1X40.)
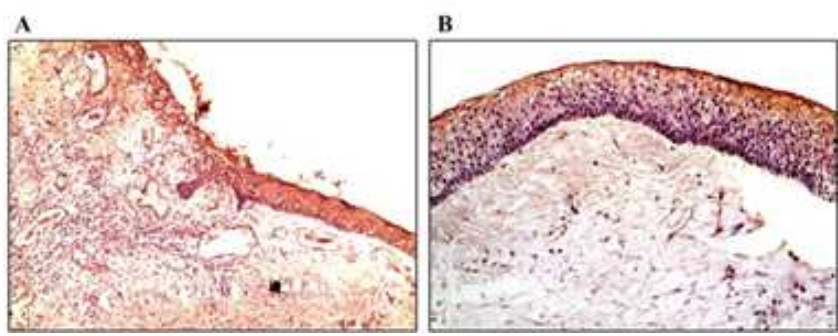

Figure 7. A photomicrograph of Keratocystic odontogenic tumor revealing diffuse immune reaction. .Notice, the budding of the epithelial cells (Laminin-1x10-Laminin-1x20)

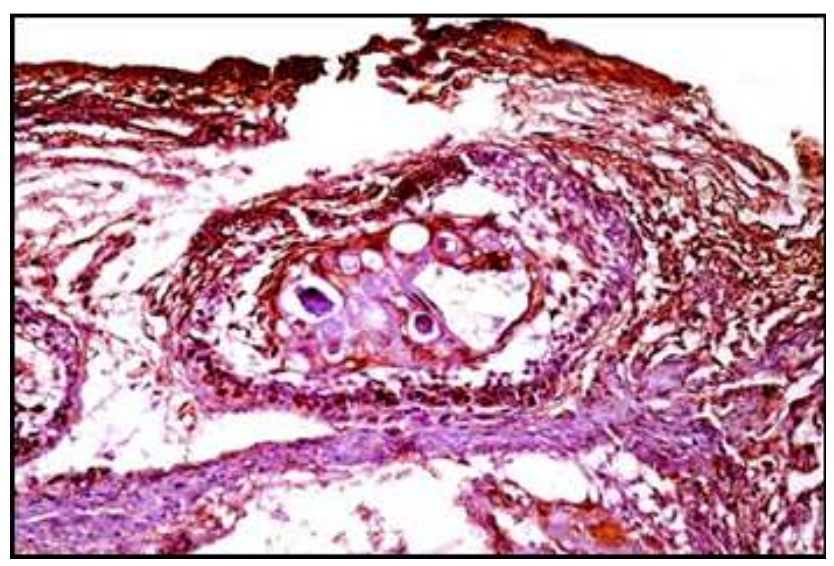

Figure 8. A photomicrograph of acanthomatous ameloblastoma showing positive immune reaction (Laminin-1x40)

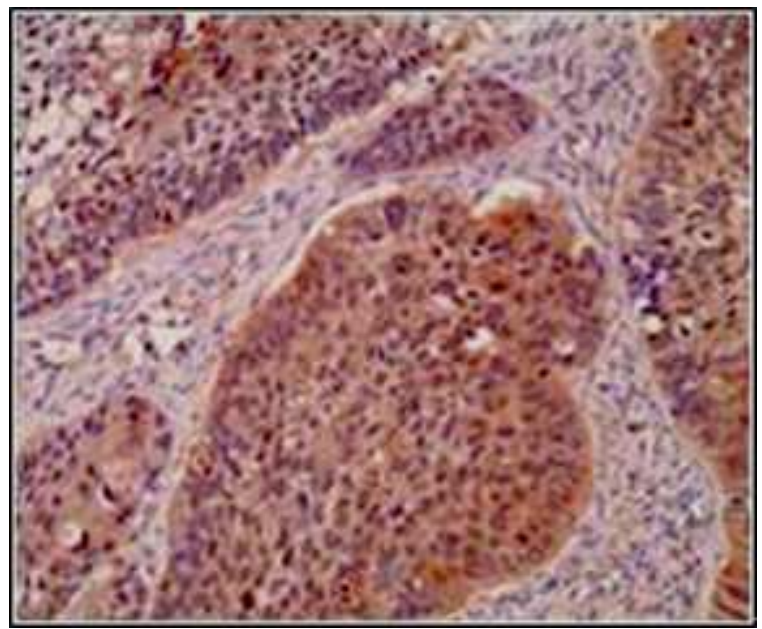

Figure 9. A photomicrograph of ameloblastic carcinoma revealing immunopossitve cytoplasmic reaction (Laminin-1x40)

\section{Discussion}

Cysts are more common in the jaws than in any other bone because of the ubiquitous presence of epithelial rests after odontogenesis. ${ }^{(11,12)}$ These lesions are often difficult to diagnose on the basis of their radiographic features alone. The final diagnosis must be accomplished based on macroscopic and microscopic examination.

In this study, it was found that the prevalence of odontogenic lesions in male is slightly more than that in female patients and the mandible was the most frequent affected side. These findings were confirmed in other studies. $^{(1,13,14)}$

An interesting finding in the current study was the prevalence of Keratocystic odontogenic tumor constituting $32.8 \%$ of studied oral lesions. Inflammatory radicular cyst constitutes $25.8 \%$, followed by dentigerous cyst $(12.5 \%)$ and finally Gorlin cyst $3.1 \%$. Other studies had different results where inflammatory cysts constitute the most prevalent odontogenic lesion ${ }^{(7,8,9)}$ The second most frequent odontogenic lesion varies between dentigerous cyst ${ }^{(15)}$ and Keratocystic odontogenic tumor ${ }^{(1)}$ according to the study. 
The variation in prevalence could be contributed to ethnic origin of individuals. Furthermore, to our knowledge, not all surgically removed cysts are sent to be examined histologically. In this study it was found that the prevalence of unicystic ameloblastoma (34\% of all cases of ameloblastoma) slightly less than the solid forms (43\%) in the last four years.

In a research carried out in Chiai (2010), it was found that both types (unicystic and solid forms) of cysts were nearly equal. ${ }^{(14)}$

In previous literatures, ameloblastic carcinomas were considered as extremely rare malignant odontogenic epithelial neoplasm's that may arouse de novo or from a pre-existing odontogenic lesion. ${ }^{(4,17)}$

Nevertheless, the present work revealed that the prevalence of ameloblastic carcinomas in relation to the ameloblastoma were considered relatively high (18\%) having no enough data showing whether they were recurrent cases or arouse de novo.

Of the approximately15 laminin trimmers described in mammals, laminin-1 expression seems to be largely limited to epithelial basement membranes. It appears early during epithelial morphogenesis in most tissues of the embryo, and remains present as a major epithelial laminin in some adult tissues. Previous organ culture studies with embryonic tissues have suggested that laminin-1 is important for epithelial development. ${ }^{(18)}$

The expression of basement membrane components, including laminins-1 has previously been studied in odontogenic lesions ${ }^{(5,18,19)}$ Puangwan et al. ${ }^{(20)}$ had focused on the importance of the basement membrane proteins and its role in odontogenic tumors since many basement membrane proteins are expressed in several types of odontogenic tumors. In the present research, all the examined odontogenic cysts and tumors showed positivity of laminin-1 in the basement membrane. This was in agreement with other studies. ${ }^{(5,19)}$

Moreover, strong positivity of laminin 1 in the cytoplasm, in some of the studied odontogenic cysts as well as begnine and malignant odontogenic tumors was consistently found. Taking in consideration that most of these lesions are considered to have an aggressive behavior. ${ }^{(3,4,11,15,16,21-23)}$

These findings support our previous notion that laminin-1 is expressed in the epithelial cells of odontogenic origin and may be a marker of odontogenic tumors. ${ }^{(4,18-20)}$

However, further studies utilizing more advanced methodological tools are recommended

It could be concluded that:

- Incidence of odontogenic cysts, ameloblastoma and Keratocystic odontogenic tumor in male is slightly more than that in female, and the mandible was the most frequent affected side.

- Keratocystic odontogenic tumor and unicystic ameloblastoma were considered the most prevalent odontogenic tumors.

- There is an increase in the incidences of ameloblastic carcinoma in the last four years.
- The benign nature of some odontogenic cysts and the aggressive behavior of others could be explained by the expression of laminin- 1 .

\section{References}

[1] B. G. Koseoglu, B. Atalay and M. A. Erdem, "Odontogenic Cysts: a Clinical Study of 90 Cases," Journal of Oral Science, vol. 46, No. 4, 2004, pp. 253-257.

[2] F. Selvil, M. S. Tekkesin, S. Cakarer 1, S. C. Isler1 and C. Keskin, "Keratocystic odontogenic Tumors: Predictive Factors of Recurrence by Ki-67 and AgNORLabelling," Int J Med Sci 2012; 9(4):262-268. doi:10.7150/ijms.4243

[3] J. A. Regezi, "Odontogenic Cysts, Odontogenic Tumors, Fibroosseous, and Giant Cell Lesions of the Jaws," Mod Pathol, vol. 15, No. 3, 2002, pp. 331-341

[4] S. L. Avon, J. McComb and C. Clokie, "Ameloblastic carcinoma: Case report and literature review," J Can Dent Assoc Vol. 69, 2003, 573-576.

[5] S. Poomsawat, J. Punyasingh and W. Weerapradist, "Expression of Basement Membrane Components in Odontogenic Cysts," Oral Diseases, Vol. 12, 2006, pp. 290-296.

[6] M. S. Ayoub, H. M. Baghdadi and M. El-Kholy, "Immunohistochemical Detection of Laminin-1 and Ki-67 in Radicular Cysts and Keratocystic odontogenic Tumors," BMC Clinical Pathology, vol. 11, 2011, pp. 4

[7] A. de Arcangelis, O. Lefebvre, A. Mechine-Neuville, C. Arnold, A. Kline and L. Remy, "Overexpression of Laminin Alpha1 Chain in Colonic Cancer Cells Induces an Increase in Tumor Growth," Int J Cancer, vol. 94, 2001, pp. 44-53.

[8] S. Nuñez-Urrutia, R. Figueiredoand C. Gay-Escoda, "Retrospective Clinicopathological study of 418 odontogeniccysts," Med Oral Patol Oral Cir Bucal," vol. 15, 2010, pp. e767-773.

[9] L. B. de Souza, M. A. Gordón-Núñez, C. F. Nonaka, M. C. de Medeiros, T. F. Torres and G. B. Emiliano, "Odontogeniccysts: Demographic Profile in a Brazilian Population Over a 38-Year Period," Med Oral Patol Oral CirBucal, vol. 15, 2010, pp. e583-590.

[10] A. Açikgöz, E. Uzun-Bulut, B. Özdenand K. Gündüz, "Prevalence and Distribution of Odontogenic and NonodontogenicCysts in a Turkish Population," Med Oral Patol Oral Cir Bucal, vol. 17, No. 1, 2012, pp. e108-115.

[11] http://www.medicinaoral.com/medoralfree $01 / \mathrm{v} 17 \mathrm{i} 1 /$ medoral v17i1p108.pdf

[12] M. A. Tawfik and M. M. Zyada, "Odontogenic Tumors in Dakahlia, Egypt: Analysis of 82 Cases," Oral Surgery, Oral Medicine, Oral Pathology, Oral Radiology and Endodontology," vol. 109, No. 2, 2010, pp. e67-e73.

[13] R. A. Cawson, E. W. Odell and S. Porter, "Cawson' Essentials of Oral Pathology and Oral Medicine," 7thed, Churchill Livingstone, Edinburgh, 2002, pp. 102-121.

[14] J. A. Regezi, J. J. Sciubba, R. C. K. Jordan, "Oral Pathology: Clinical Pathologic Correlations," 4thed, WB Saunders, St 
Louis, 2003, 241-254.

[15] A. B. Bataineh, M. A. Rawashdeh and M. A. Al Qudah, "The Prevalence of Inflammatory and Developmental Odontogenic Cysts in a Jordanian Population: a Clinicopathologic Study," Quintessence Int, vol. 35, No. 10, 2004, pp. 815-819.

[16] V. Ebenezer and B. Ramalingam, "A Cross-Sectional Survey of Prevalence of OdontogenicTumours," J Maxillofac Oral Surg, vol. 9, No. 4, 2010, 369-374.

[17] R. S. Ramesh, S. Manjunath, T. H. Ustad, S. PaisandK. Shivakumar, Unicysticameloblastoma of the mandible - an unusual case report and review of literature Head \& Neck Oncology vol. 2, 2010, p.1

[18] http://www.headandneckoncology.org/content/2/1/1.

[19] R. Datta, J. S. Winston, G, Diaz-Reyes, T. R. Loree, L. Myers, M. A. Kuriakose, et al, "Ameloblastic Carcinoma: Report of an Aggressive Case with Multiple Bony Metastases," Am J Otolaryngol, vol. 24, 2003, pp. 64-69.

[20] P. Ekblom, P, Lonai, J. F. Talts, "Expression and Biological Role of Laminin-1. Matrix Biol," vol. 22, No. 1, 2003, pp. $35-47$.
[21] S. Poomsawat, J. Punyasingh and P. Vejchapipat, Expression of basement membrane components in odontogenic tumors Oral Surgery, Oral Medicine, Oral Pathology, Oral Radiology and Endodontology vol. 104, No. 5, 2007, pp 666-675.

[22] P. Lapthanasupkul, S. Poomsawat and J. Chindasombatjaroen, "Investigation of Basement Membrane Proteins in a Case of Granular Cell Ameloblastoma," International Journal of Oral Science, vol. 4, 2012, pp 45-49.

[23] S. C. A. Gurgel, G. E. A. Ramos, A. L. Melo, B. C. Schlaepfer, R. O. de Souza, C. M. Oliveira and J. N. dos Santos, "Immunolocalisation of laminin-1 in Keratocystic odontogenic tumors," ActaHistochem, vol. 112, No. 6, 2010, pp. 624-629.

[24] H. H. Araújo,R. José, , V. Thiago, L.M.Guedes, É.J.Dantas, Glandular odontogenic cyst: case report and review of diagnostic criteria, Journal of Cranio-Maxillofacial Surgery, vol. 40, No. 2, 2012, pp e46-e50.

[25] P.Aggarwal, S.Saxena. Aggressive growth and neoplastic potential of dentigerous cysts with particular reference to central mucoepidermoid carcinoma. $\mathrm{Br} \mathrm{J}$ Oral MaxillofacSurg, vol. 49, No. 6, 2011, pp e36-9 